\title{
Bilateral sagittal split mandibular osteotomies for enhanced exposure of the anterior cervical spine in children: technical note
}

\author{
Michael Karsy, MD, PhD, ${ }^{1}$ Neal Moores, MD, ${ }^{2}$ Faizi Siddiqi, MD, ${ }^{2}$ Douglas L. Brockmeyer, MD, ${ }^{1}$ and \\ Robert J. Bollo, MD1
}

1Department of Neurosurgery, Division of Pediatric Neurosurgery, and 'Department of Surgery, Division of Plastic Surgery, University of Utah School of Medicine, Primary Children's Hospital, Salt Lake City, Utah

\begin{abstract}
The bilateral sagittal split mandibular osteotomy (BSSMO), a common maxillofacial technique for expanding the oropharynx during treatment of micrognathia, is a rarely employed but useful adjunct to improve surgical access to the ventral cervical spine in children. Specifically, it provides enhanced exposure of the craniocervical junction in the context of midface hypoplasia, and of the subaxial cervical spine in children with severe kyphosis. The authors describe their technique for BSSMO and evaluate long-term outcomes in patients.

The pediatric neurosurgical database at a single center was queried to identify children who underwent BSSMO as an adjunct to cervical spine surgery over a 22-year study period (1993-2015). The authors retrospectively reviewed clinical and radiographic data in all patients.

The authors identified 5 children (mean age $5.3 \pm 3.1$ years, range 2.1-10.0 years) who underwent BSSMO during cervical spine surgery. The mean clinical follow-up was $3.0 \pm 1.9$ years. In 4 children, BSSMO was used to increase the size of the oropharynx and facilitate transoral resection of the odontoid and anterior decompression of the craniocervical junction. In 1 patient with subaxial kyphosis and chin-on-chest deformity, BSSMO was used to elevate the chin, improve anterior exposure of the subaxial cervical spine, and facilitate cervical corpectomy. Careful attention to neurovascular structures, including the inferior alveolar nerve, lingual nerve, and mental branch of the inferior alveolar artery, as well as minimizing tongue manipulation and compression, are critical to complication avoidance.
\end{abstract}

The BSSMO is a rarely used but extremely versatile technique that significantly enhances anterior exposure of the craniocervical junction and subaxial cervical spine in children in whom adequate visualization of critical structures is not otherwise possible.

https://thejns.org/doi/abs/10.3171/2016.11.PEDS16530

KEY WORDS odontoidectomy; transoral; mandibular osteotomy; basilar invagination; spine; surgical technique

$\mathrm{V}$ ARIOUS surgical approaches for odontoid resection and decompression of the foramen magnum have been described in the adult literature, including the open transoral approach, ${ }^{35}$ endoscopic combined transoral and transnasal approach, ${ }^{17}$ extreme lateral transatlas approach, ${ }^{36}$ and robot-assisted transoral approach ${ }^{16}$ However, limited data are available regarding the optimal surgical approach in children. Although microscopic transoral approaches, ${ }^{15}$ as well as endoscopic endonasal and transcervical approaches, ${ }^{11,18,20,26,31}$ have been described in the pediatric population, these techniques may be technically challenging because of the smaller size of the oro- nasopharynx. ${ }^{38}$ These difficulties are often exacerbated in the context of associated congenital anomalies, such as midface hypoplasia, which can be encountered in children with abnormalities of the cervical spine. Furthermore, anterior access to the subaxial cervical spine can be challenging when small anatomy is combined with severe cervical kyphosis or chin-on-chest deformity.

A variety of pathological conditions may be treated by anterior, transoral approaches in children. Craniocervical kyphosis with basilar invagination of the odontoid can be a potential congenital cause of cervical myelopathy. ${ }^{3,4}$ Likewise, certain congenital disorders in children, such 
as Down syndrome, ${ }^{1,5}$ Morquio syndrome, ${ }^{7,32,34}$ Williams syndrome, ${ }^{8}$ and connective tissue disorders, ${ }^{6}$ often result in ligamentous laxity and compression of the cervicomedullary junction. One series of 280 patients younger than 16 years of age who underwent transoral-transpalatopharyngeal odontoidectomies included 202 cases of basilar invagination, 28 cases of proatlas segmentation anomalies, 30 cases of dystopic os odontoideum, 7 cases of spinal tumors, and 7 cases of Down syndrome with cervicomedullary compression..$^{21}$

Bilateral sagittal split mandibular osteotomy (BSSMO) has been a useful approach in adults and orthognathic surgery. $2,22,24,28,37$ Initially described in the late 1800 s and made more popular in the 1960 s, it has been used for correction of malocclusive disorders (e.g., horizontal mandibular excess or deficiency) as well as in mandibular asymmetry. ${ }^{2,22}$ Although 5 individual cases of BSSMO for odontoidectomy have been reported in adult patients with juvenile rheumatoid arthritis, ${ }^{13}$ Klippel-Feil syndrome, and congenital occipitocervical instability, ${ }^{37} \mathrm{BSSMO}$ has not been previously reported as a method to improve anterior access to the subaxial cervical spine in young children with cervical chin-on-chest deformities. Herein, we describe our surgical technique and present 5 pediatric cases with long-term follow-up, in which BSSMO was used to provide enhanced surgical access to the craniocervical junction and subaxial cervical spine.

\section{Methods \\ Patients}

After obtaining institutional review board approval, we retrospectively reviewed the pediatric neurosurgical database at Primary Children's Hospital and the University of Utah to identify children who underwent BSSMO as an adjunct to anterior cervical spine surgery between 1993 and 2015 .

\section{Surgical Evaluation}

Preoperative evaluation for inpatients undergoing BSSMO as an adjunct to anterior cervical decompression included anterior and lateral photographs with the mouth closed and while smiling to document presurgical facial symmetry. Panoramic radiographs were obtained to evaluate the stage of dental development and mandibular anatomy. Cranial radiographs were sometimes obtained, with various methods of described cephalometric analysis. A cast of the maxilla and mandible was sometimes used to supplement radiographs and provide a 3D view of the jaw.

\section{Bilateral Sagittal Split Mandibular Osteotomy}

BSSMO was performed by a single pediatric plastic surgeon in all patients at the beginning of the surgical procedure prior to the neurosurgical portion of the case (Fig. 1A). For 2 patients (Cases 1 and 3), elective tracheostomy was performed before BSSMO for airway protection as part of a planned 2-stage anterior-posterior procedure. One patient (Case 4) had prior elective tracheostomy because of macroglossia, limited oral access, and compromised airway. Otherwise, the patients were intubated with a reinforced nasotracheal or oral endotracheal tube with fiberoptic assistance. Patients were then positioned supine with the head on a padded horseshoe headrest; the face was prepared with povidone solution, and the mouth was washed with $0.12 \%$ chlorhexidine gluconate oral rinse. The lower buccal sulcus was infiltrated bilaterally with $0.25 \%$ lidocaine and 1:400,000 epinephrine. Bilateral inferior alveolar nerve blocks were also frequently used.

The anterior border of the ramus and external oblique ridge were identified intraorally. An incision was created along the mandibular ramus halfway up the anterior border beyond the angle of the mandible medially. Dissection was carried to the periosteum, and a periosteal elevator was used to expose the lateral and medial ramus and angle. The lingula of the mandible, identifying the anterior border of the mylohyoid groove, was identified. Osteotomies were then created with a piezoelectric ultrasonic system (Synthes) (Fig. 1B and C). Cuts were made initially on the buccal aspect of the angle, and then to the lingual aspect of the ramus posterior to the mylohyoid canal in the vertical plane. Subsequently, an osteotomy was made in an anterior-posterior direction in line with the molars to bisect the ramus and angle in the sagittal plane. Great care
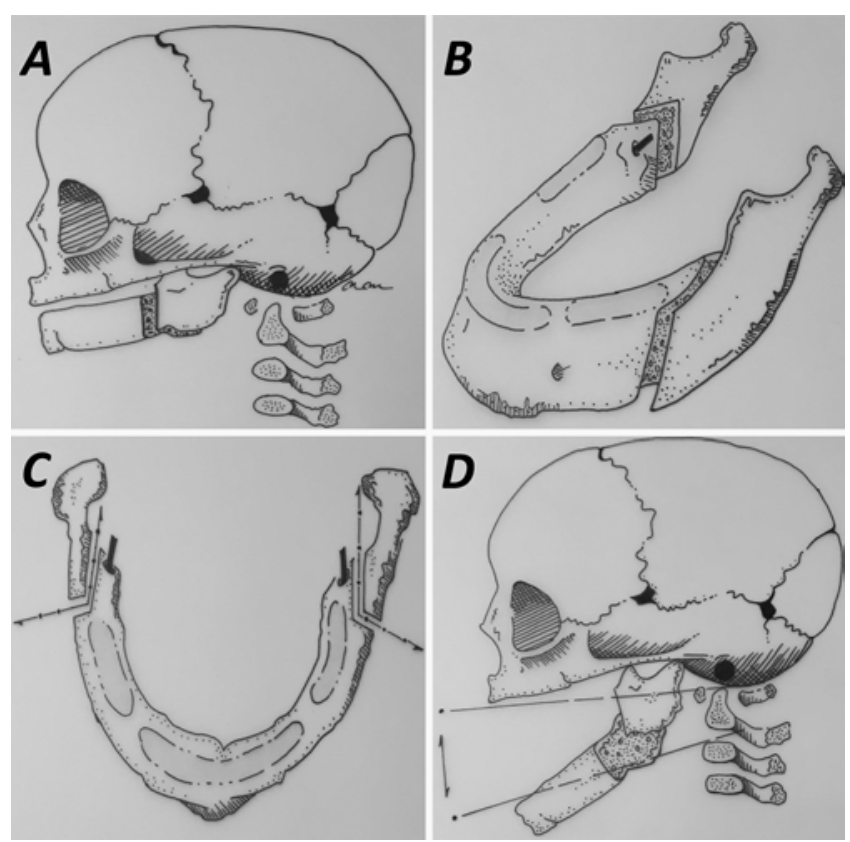

FIG. 1. Anatomical illustrations depicting the BSSMO. A: Lateral view of a pediatric skull demonstrating the position of the BSSMO osteotomy anterior to the coronoid process in a superoinferior plane. The skull has a short mandibular ramus that limits oral accessibility. B: Oblique view of the mandible further demonstrates the BSSMO osteotomy in a superoinferior direction posterior to the mylohyoid groove and mandibular foramen (thick black line). C: Superior view of the mandible showing the posteroanterior direction of the BSSMO osteotomy (arrows) lateral to the mandibular foramen (thick black lines). Lateral view of the pediatric skull and superior cervical spine, demonstrating range of mandibular mobility after BSSMO, allowing improved exposure to the craniocervical junction or subaxial cervical spine. D: Lateral view of the pediatric skull and superior cervical spine, demonstrating range of mandibular mobility after BSSMO, allowing improved exposure to the craniocervical junction or subaxial cervical spine. Copyright University of Utah Department of Neurosurgery. Published with permission. 
was taken to remain lateral to the mandibular nerve and mental branch of the inferior alveolar artery. Osteotomies were completed with an osteotome to mobilize the jaw.

For transoral odontoid resection, a low-profile self-retaining retractor system was placed for distraction of the mandibular sections, and a separate blade was used to retract the tongue. Additional visualization may be obtained by retracting the soft palate into the nasopharynx or by dividing it. Intraoperative fluoroscopy was used to identify the position of the odontoid. The overlying mucosa was incised vertically and divided, and then an odontoidectomy was completed using the drill and rongeur. After resection, the oral mucosa was closed with fast-absorbing suture.

For access to the subaxial cervical spine (Case 5), the patient was placed in Halter traction after the jaw was mobilized, thereby increasing the amount of anterior cervical exposure. Once the neurosurgical procedure was completed, the mandibular segments were reapproximated with mandibular plates and unicortical screws. Postoperative radiographs of the face were obtained to identify anatomical alignment, and panoramic radiographs are obtained to ensure proper dental alignment. Follow-up panoramic radiographs were obtained at 1 year to ensure facial alignment without deformity, and cervical flexion-extension radiographs were obtained to demonstrate dynamic stability.

\section{Complication Management}

Potential complications with the BSSMO can often be avoided if recognized early. Placement of a tongue retractor during the procedure can potentially result in swelling due to tissue ischemia. This can be avoided by a combination of efficient completion of the intended surgical procedure as well as intermittent relaxation of the retractor to allow perfusion of the tongue. Injury to the inferior alveolar nerve, lingual nerve, or mental branch of the inferior alveolar artery can be caused by poorly placed sagittal mandibular cuts or overdistraction of the mandible. Attention to the level of distraction and placement of the sagittal cuts lateral to the alveolar nerve and artery is key to avoiding these complications. Postmandibular fixation can also yield anatomical malalignment and injury to dentition, but the involvement of an experienced craniofacial plastic surgeon and attention to postsurgical dental imaging are usually enough to prevent malalignment. Postoperative infection and wound breakdown are more likely with a transoral approach but can be avoided by careful preoperative oral decontamination as well as close postsurgical wound follow-up.

\section{Results}

We identified 5 patients with a mean age of $3.1 \pm 3.4$ years (mean $\pm \mathrm{SD}$ ) at presentation and $5.3 \pm 3.1$ years (range 2.1-10.0 years) at the time of surgery. The mean follow-up was $3.0 \pm 1.9$ years. The mean height was 86.12 $\pm 18.3 \mathrm{~cm}$, and the mean weight was $13.1 \pm 6.7 \mathrm{~kg}$. Demographic, clinical, surgical, and radiographic data are detailed in Table 1.

TABLE 1. Demographic and clinical characteristics of 5 patients in whom BSSMO was used to expand access to the subaxial cervical spine

\begin{tabular}{|c|c|c|c|c|c|c|c|c|}
\hline $\begin{array}{l}\text { Case } \\
\text { No. }\end{array}$ & $\begin{array}{l}\text { Age at } \\
\text { BSSMO } \\
\text { (yrs), Sex }\end{array}$ & $\begin{array}{l}\text { Height } \\
(\mathrm{cm})\end{array}$ & $\begin{array}{l}\text { Weight } \\
(\mathrm{kg})\end{array}$ & Indications & Complications & $\begin{array}{l}\text { Associated Syndrome/ } \\
\text { Conditions }\end{array}$ & Associated Surgeries & $\begin{array}{l}\text { FU } \\
\text { (yrs) }\end{array}$ \\
\hline 1 & $10.0, \mathrm{M}$ & 117 & 24.8 & $\begin{array}{l}\text { Basilar invagination w/ } \\
\text { myeloradiculopathy }\end{array}$ & $\begin{array}{l}\text { Posterior pharyngeal } \\
\text { wound dehiscence } \\
\text { \& MSSA infection }\end{array}$ & $\begin{array}{l}\text { Monosomy 10p, trisomy 11q, } \\
\text { intraventricular hemor- } \\
\text { rhage \& hydrocephalus }\end{array}$ & $\begin{array}{l}\text { Tracheostomy, occipito- } \\
\text { cervical arthrodesis to } \\
\text { C-3 w/ autograft }\end{array}$ & 4.6 \\
\hline 2 & $6.3, \mathrm{~F}$ & 79.0 & 9.6 & $\begin{array}{l}\text { Basilar invagination } \\
\text { w/ torticollis, bulbar } \\
\text { symptoms, \& my- } \\
\text { elopathy }\end{array}$ & $\begin{array}{l}\text { Hardware revision \& } \\
\text { removal, infected } \\
\text { shoulder pressure } \\
\text { ulcers due to } \\
\text { cervical collar }\end{array}$ & $\begin{array}{l}\text { Unknown syndrome: } \\
\text { torticollis, occipitocervical } \\
\text { malformation, Klippel-Feil, } \\
\text { velopharyngeal insuf- } \\
\text { ficiency }\end{array}$ & $\begin{array}{l}\text { Occipitocervical arthrod- } \\
\text { esis to C-3 w/ autograft }\end{array}$ & 4.8 \\
\hline 3 & 3.3, M & 85.0 & 12.0 & $\begin{array}{l}\text { Complex Chiari w/ bas- } \\
\text { ilar invagination w/ } \\
\text { syringohydromyelia \& } \\
\text { multiple congenital ab- } \\
\text { normalities presenting } \\
\text { w/ bulbar symptoms }\end{array}$ & $\begin{array}{l}\text { Hardware revision, } \\
\text { wound washout, } \\
\text { CSF leak }\end{array}$ & $\begin{array}{l}\text { Unknown syndrome: } \\
\text { complex Chiari, hydro- } \\
\text { cephalus, arachnodactyly, } \\
\text { chordee, scrotal webbing, } \\
\text { \& distal arthrogryposis }\end{array}$ & $\begin{array}{l}\text { Prior occipitocervical } \\
\text { arthrodesis to C-2 } \\
\text { w/o decompression, } \\
\text { revision fusion w/ auto- } \\
\text { graft, syringoperitoneal } \\
\text { shunt, VP shunt }\end{array}$ & 0.9 \\
\hline 4 & $2.1, F$ & 81.0 & 11.3 & $\begin{array}{l}\text { Worsening ventila- } \\
\text { tory dependence \& } \\
\text { dysphagia }\end{array}$ & $\begin{array}{l}\text { Hardware lucency } \\
\text { after occipitocervi- } \\
\text { cal fusion }\end{array}$ & $\begin{array}{l}\text { Beare-Stevenson syndrome, } \\
\text { multisuture craniosynosto- } \\
\text { sis \& cloverleaf defor- } \\
\text { mity, midface hypoplasia, } \\
\text { hydrocephalus }\end{array}$ & $\begin{array}{l}\text { Repair of craniosynosto- } \\
\text { sis, Chiari decompres- } \\
\text { sion } \times 2 \text {, VP shunt } \\
\text { placement }\end{array}$ & 1.0 \\
\hline 5 & $4.8, M$ & 68.6 & 8.0 & $\begin{array}{l}\text { Severe cervical kypho- } \\
\text { sis, ventral cord com- } \\
\text { pression, progressive } \\
\text { syringomyelia }\end{array}$ & $\begin{array}{l}\text { Occipital wound } \\
\text { pressure ulcer } \\
\text { managed conser- } \\
\text { vatively }\end{array}$ & $\begin{array}{l}\text { Unknown syndrome: Klippel- } \\
\text { Feil, intestinal malrotation, } \\
\text { fused It kidney, absence of } \\
\text { C-1 \& C-2 }\end{array}$ & $\begin{array}{l}\text { Prior occiput-T4 posterior } \\
\text { spinal fusion \& C5-6 \& } \\
\text { C6-7 partial discecto- } \\
\text { my w/o instrumentation }\end{array}$ & 3.4 \\
\hline
\end{tabular}

FU = follow-up; MSSA = methicillin-sensitive Staphylococcus aureus. 


\section{Case 1}

A 10 -year-old boy with monosomy 10p, trisomy 11q, developmental delay, and shunt-treated hydrocephalus secondary to intraventricular hemorrhage presented with progressive right hemiparesis, head tilt to the right side, and decreased activity from baseline (Fig. 2). On examination, he had no cranial nerve deficits or bulbar symptoms, and his right upper extremity demonstrated $5 / 5$ strength. He was myelopathic with spastic diplegia, including a positive Hoffmann sign and 3+ hyperreflexia in both lower extremities. MRI of the cervical spine demonstrated craniocervical settling, basilar invagination, and ventral spinal cord compression with T2 signal abnormality. The patient was admitted to the hospital, and an elective tracheostomy was performed because it was expected that a 2 -stage anteriorposterior approach would be necessary for decompression of the cervical spine. The patient initially underwent a posterior craniocervical arthrodesis from the occiput to C-3. On hospital Day 8, he underwent BSSMO followed by transoral resection of the odontoid. During internal fixation of the mandible, dental impressions were made, and a splint was applied to correct alignment. The patient's postoperative course was complicated by posterior pharyngeal wound dehiscence and infection with methicillinsensitive Staphylococcus aureus, requiring intravenous antibiotics and surgical wound debridement on postoperative Day 11. At last clinical follow-up 4.6 years after surgery, the patient's dexterity and strength in all extremi- ties were significantly improved, and he was ambulating without a wheelchair. Follow-up imaging of the cervical spine demonstrated decompression of the craniocervical junction without hardware malfunction (Fig. 2).

\section{Case 2}

A 6.3-year-old girl presented with progressively worsening bulbar symptoms, including dysphagia, sleep apnea, and bowel and bladder incontinence. She had a history of Klippel-Feil abnormality, craniocervical kyphosis, and torticollis treated by a previous occipitocervical (occiputC3) posterior spinal fusion at 16 months of age and subsequent hardware removal at 4 years in the setting of a mature fusion construct (Fig. 3). CT imaging of the cervical spine demonstrated occipitalization of the atlas and severe basilar invagination with retroflexion of the odontoid. MRI demonstrated severe ventral brainstem compression and T2 signal abnormality in the high cervical cord. The patient underwent BSSMO and transoral odontoidectomy with ventral decompression of the craniocervical junction with uncomplicated postoperative course. At last followup 4.8 years after surgery, she had significant improvement in swallowing, mobility, and strength (Fig. 3).

\section{Case 3}

This 3.3-year-old boy had a history of shunt-treated hydrocephalus, occiput-C2 posterior spinal fusion, and multiple congenital anomalies including arachnodactyly,
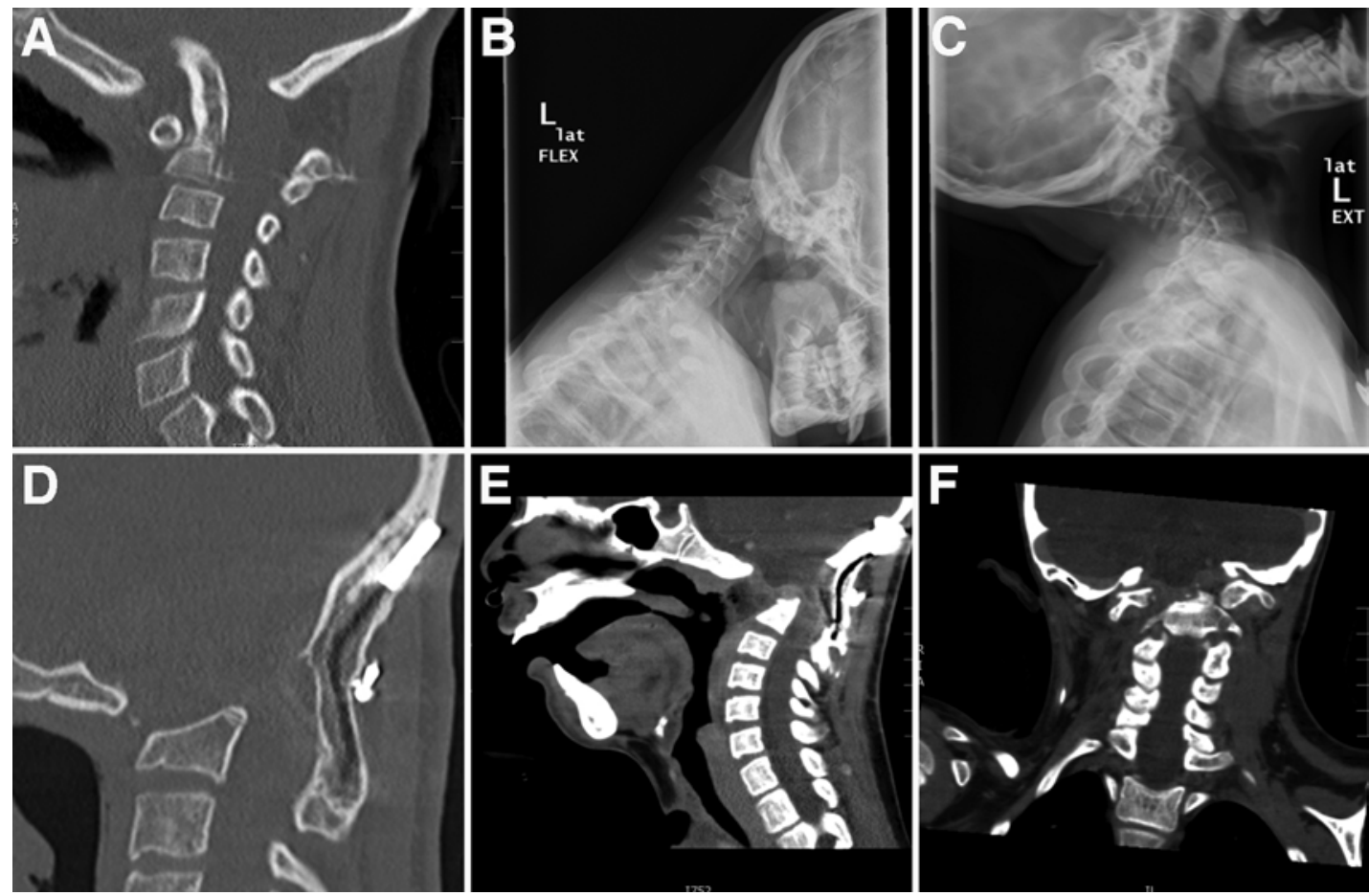

FIG. 2. Case 1. This 9-year-old boy presented with severe compression of the cervicomedullary junction with progressive worsening strength and dexterity of his upper extremities. A: Preoperative CT of the cervical spine showing significant upward displacement and retroflexion of the dens with narrowing of the foramen magnum. B and C: Preoperative flexion and extension radiographs showing marked instability of the occipitocervical junction. D: Sagittal cervical CT scan demonstrating fusion from the occiput to C-1 along a posterior rib allograft. E and F: Postoperative sagittal (E) and coronal (F) CT scans, obtained after occipitocervical fusion and a BSSMO approach for transoral odontoidectomy, showing increased space around the cervicomedullary junction. Coronal imbalance was improved compared with preoperative imaging. 

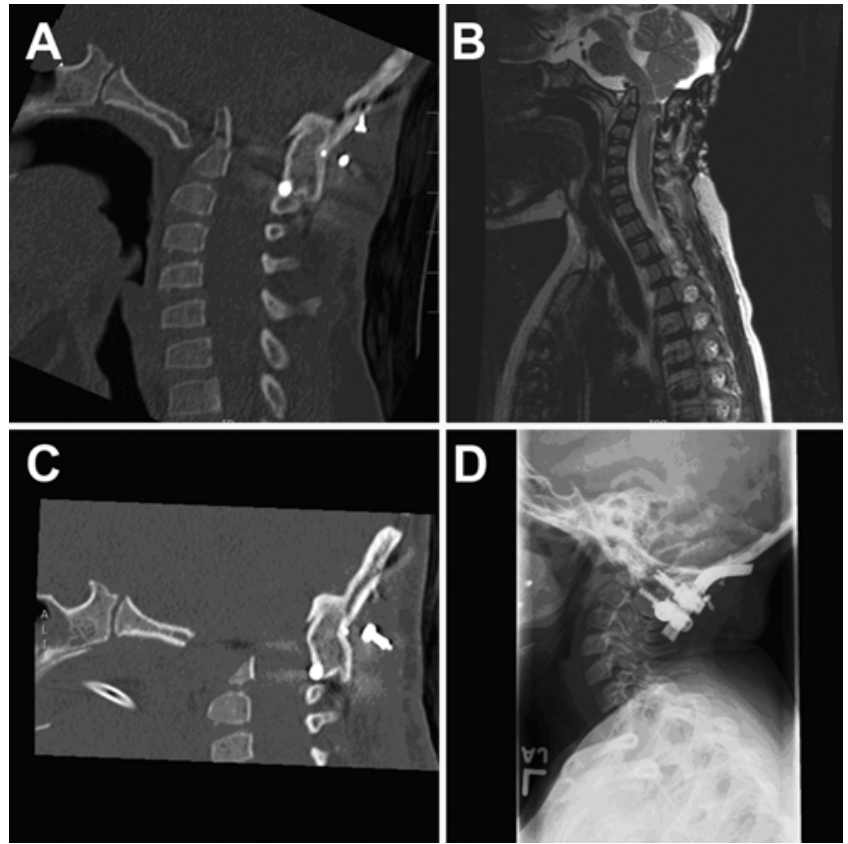

FIG. 3. Case 2. A 6-year-old girl presented with worsening dysphagia, sleep apnea, and incontinence 4 years after occipitocervical fusion for torticollis and craniovertebral junction malformation. A: CT scan obtained after occipitocervical fusion and re-presentation for bulbar symptoms, showing a persistent and protuberant dens. B: T2-weighted MR image showing significant kinking of the cervicomedullary junction with basilar invagination of the dens. C: Sagittal CT scan obtained after odontoidectomy, showing good decompression. D: Follow-up radiograph showing correct hardware placement with no complication.

chordee, scrotal webbing, and distal arthrogryposis. He presented with progressive bulbar dysfunction, including dysphagia and myelopathy with severe upper-extremity weakness. Imaging demonstrated a Chiari I malformation with basilar invagination, holocord syringomyelia, and a low-lying conus (Fig. 4). The patient underwent a planned anterior-posterior approach beginning with elective tracheostomy followed by BSSMO and transoral odontoidectomy with ventral brainstem decompression. A tracheostomy was performed because the patient had a prior history of difficult intubation. He subsequently underwent posterior craniocervical decompression including suboccipital craniectomy, C-1 laminectomy, duraplasty, and instrumented occiput-C2 fusion with rib autograft. A lumbar laminectomy for release of a tethered spinal cord was performed in the same surgery. The patient was discharged home and was neurologically stable. Six months after surgery, he developed a wound infection that required removal of right craniocervical instrumentation because of hardware failure and surgical debridement. After the infection was treated, he underwent placement of a syringoperitoneal shunt to address persistent symptomatic syringomyelia. Three months later, he underwent a reexploration and revision of his suboccipital craniectomy, revision of the occipitocervical arthrodesis, removal of the syringoperitoneal shunt, and placement of a Torkildsen shunt (fourth ventricle to subarachnoid space). He subsequently developed occipital headaches, CSF leakage from his posterior cervical wound, and wound infection. Treat-
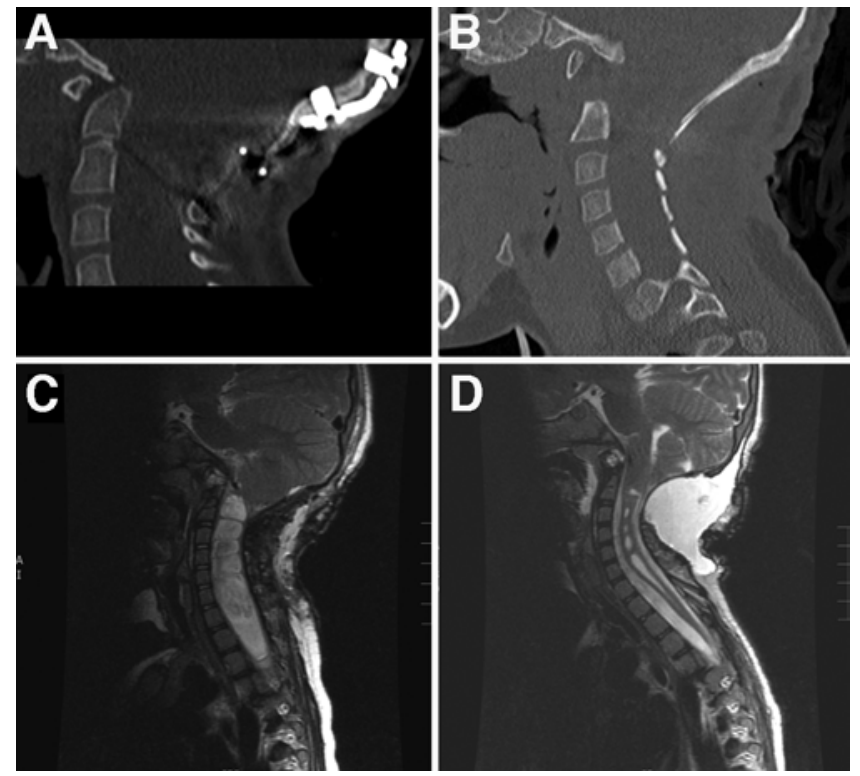

FIG. 4. Case 3. A 3-year-old boy with numerous congenital abnormalities presented with bulbar symptoms secondary to cervicomedullary compression and syringomyelia. A: Cervical spine CT scan obtained at initial presentation, showing the patient's prior occiput-C2 posterior fusion without decompression and narrowing of the cervicomedullary junction. B: Sagittal cervical CT scan obtained immediately after BSSMO, demonstrating previous occiput-C2 posterior fusion 1 month earlier, with improved space at the foramen magnum C: A T2-weighted MR image obtained 6 months postoperatively, because the patient was experiencing persistent symptoms, demonstrating continued enlargement of a known cervicothoracic syrinx, which was treated with a syringoperitoneal shunt. The patient underwent placement of a Torkildsen shunt (fourth ventricle to subarachnoid space) and a VP shunt. D: Sagittal T2-weighted MRI obtained 9 months postoperatively, showing improvement of the syrinx.

ment of these required 2 wound revisions, lumbar drain placement, antibiotic treatment, and placement of a new ventriculoperitoneal (VP) shunt. At the most recent follow-up (0.9 years postoperatively), his bulbar and myelopathic symptoms were significantly improved (Fig. 4).

\section{Case 4}

A 2.1-year-old girl with a history of Beare-Stevenson syndrome, ${ }^{10}$ syndromic multisuture craniosynostosis and cloverleaf deformity, midface hypoplasia, hydrocephalus, Chiari I malformation, and ventilator dependence with a tracheostomy presented with worsening brainstem function. The patient had previously undergone multisuture craniectomy, VP shunt placement, posterior cranial vault distraction, and Chiari decompression. Her dependence on mechanical ventilation was progressive, with increased difficulty swallowing and worsening sleep apnea. Imaging demonstrated severe brainstem compression (Fig. 5). In anticipation of ventral brainstem decompression, she underwent repeat craniocervical decompression and occipitocervical fusion with rib autograft at 22 months of age. Two months later, the patient underwent BSSMO and transoral odontoidectomy. She was not a candidate for endonasal odontoidectomy because of her midface hypoplasia. Her surgery was complicated by some hardware 

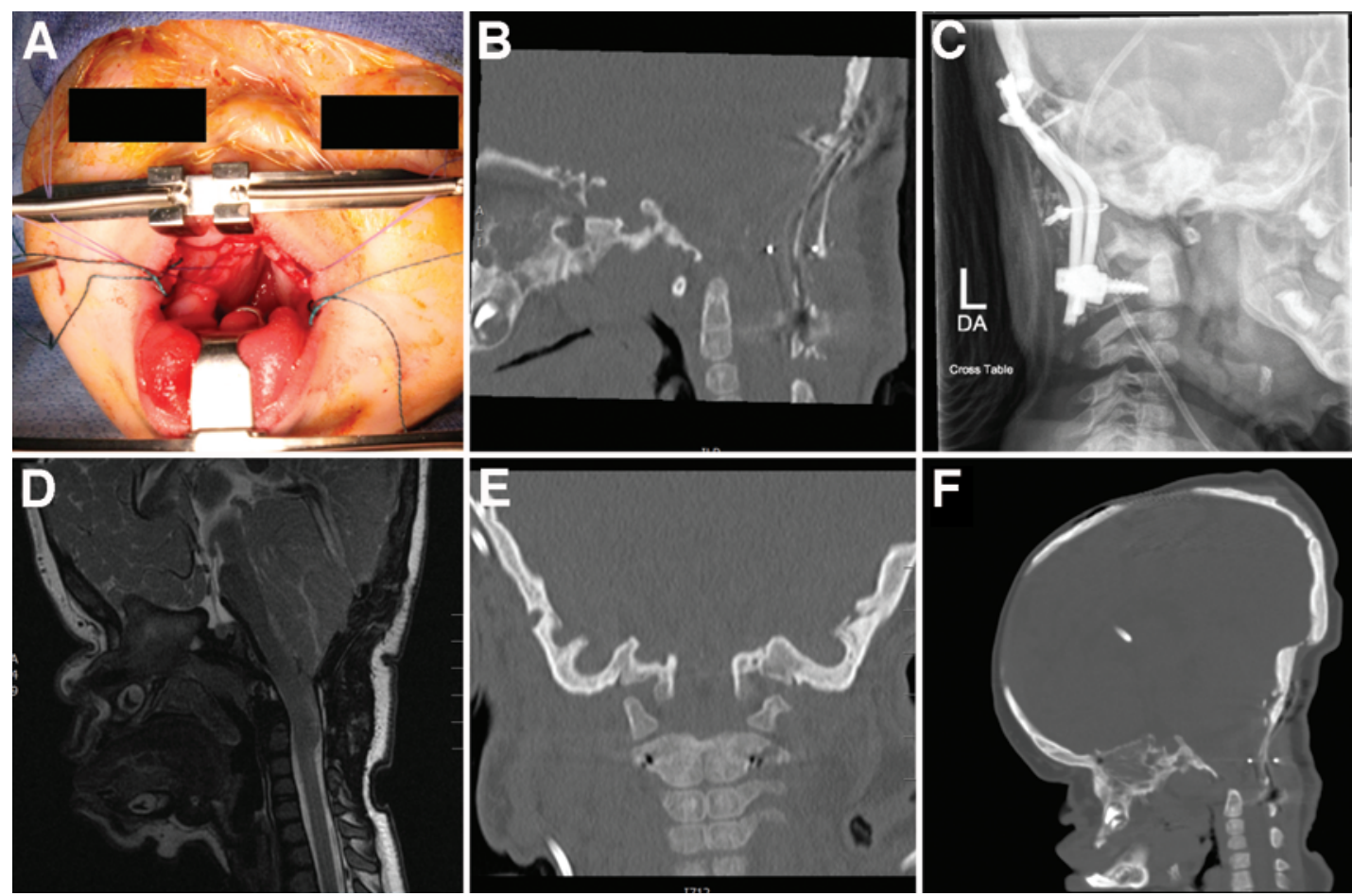

FIG. 5. Case 4. A 2-year-old girl with a history of Beare-Stevenson syndrome and multiple congenital abnormalities presented with persistent worsening ventilator dependence and dysphagia. A combined posterior fusion and odontoidectomy was planned. A: An intraoperative view after the BSSMO completion with positioning of retractors shows access to the oropharynx. B: After an occipitocervical fusion (confirmed on parasagittal images), CT scanning demonstrated that mostly soft-tissue elements impinged on the spinal cord. C: A plain film radiograph shows intact hardware with some elements of fusion. D: Two months after occipitocervical fusion, the patient underwent an odontoidectomy, which achieved good decompression of the cervicomedullary junction. $E$ and F: Coronal (E) and sagittal (F) CT scans showing adequate removal of the dens and progressive fusion of the posterior construct. Figure is available in color online only.

lucency requiring cervical collar treatment until adequate fusion was achieved, but she experienced no associated neurological deficits. At last follow-up 12 months after decompression, she had significantly improved ventilation.

\section{Case 5}

A 4.8-year-old boy presented with progressive spinal stenosis 2 years after correction of a chin-on-chest deformity. His initial presentation at 1.3 years of age included spondyloptosis at C6-7, chin-on-chest deformity, and dysphagia in the context of severe spinal cord compression (Fig. 6). Treatment included an occiput-T4 posterior spinal fusion and anterior cervical partial discectomy at C5-6 and C6-7. The patient initially did well, but 2 years later, he presented with significant C5-6 stenosis, dysphagia, failure to thrive, and syringomyelia. BSSMO was performed to facilitate an anterior approach to the lower cervical spine. The patient subsequently underwent decompressive C-5, C-6, and partial C-7 corpectomies. After an uncomplicated postoperative course, the patient returned to his hometown; follow-up images obtained 3.4 years after the BSSMO procedure showed development of a good posterior fusion mass (Fig. 6).

\section{Discussion}

We have shown that BSSMO can be a useful adjunct to improve surgical exposure of the anterior cervical spine in pediatric patients. Although the approach was developed for correction of malocclusion and mandibular asymmetry, ${ }^{22,24}$ we have used it to expand the size of the oropharynx and facilitate transoral decompression of the craniocervical junction in pediatric patients. It is especially useful in children with midface hypoplasia who may not be candidates for endonasal odontoidectomy. Case 5 demonstrates that BSSMO may also be used to mobilize the jaw and improve anterior access to the subaxial cervical spine in the context of a kyphotic deformity.

Previously developed surgical techniques to enhance surgical access to the anterior craniocervical junction, including stairstep mandibulotomy and midline glossotomy, are associated with higher morbidity and less visualization. ${ }^{23}$ One alternative to the BSSMO for congenital cervicomedullary anomalies described the use of multilevel corpectomies, stabilization with calvarial bone grafts, and a halo fixation device during the treatment of a child with Morquio syndrome. ${ }^{27}$ Other methods described include a midline mandibular osteotomy for transoral approach. ${ }^{19}$ The use of C1-2 spacers is another potential approach in reducing basilar invagination and atlantoaxial instability; however, further development in the pediatric population and especially with pediatric patients who have complex craniocervical abnormalities is required. ${ }^{14,25,29,33}$ An important potential benefit to BSSMO compared with this 

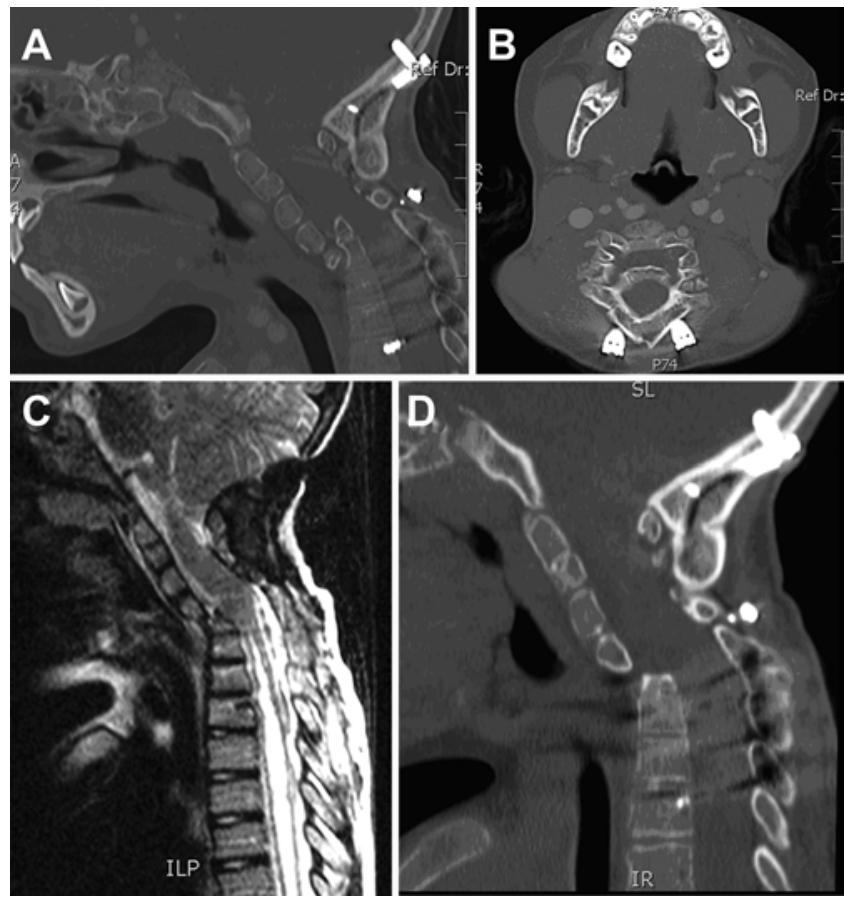

FIG. 6. Case 5. A 4-year-old boy presented with C5-6 stenosis, syringomyelia, and bulbar signs 2 years after occiput-T4 fusion for chin-onchest deformity and spondyloptosis at C6-7. A: Preoperative CT scan showing stabilized C6-7 spondyloptosis. B: Axial CT scan obtained at the level of stenosis, showing significant spinal canal stenosis and spinal cord kinking. C: Postoperative MR image obtained at follow-up, showing persistent but improved syringomyelia with increased spinal canal space at C5-6. D: Postoperative CT scan obtained at follow-up, showing good posterior fusion.

technique is the incorporation of internal fixation, thus avoiding the need for a halo. Multiple case reports and case series have explored the use of the endoscopic endonasal approach for odontoidectomies in children., ${ }^{9,18,20}$ One recent report helped identify craniocervical metrics that can be used to identify adequate surgical access to the craniocervical junction. ${ }^{38}$ However, in our cases, access to the odontoid by oral and endoscope-assisted means was not possible. The BSSMO served as a useful strategy to optimize cervical access.

A multidisciplinary team is required for successful use of this technique, including pediatric neurosurgeons, pediatric maxillofacial plastic surgeons, and pediatric dentists with experience in reconstruction. Otherwise, no other specific instrumentation or equipment is required. Regarding dental complications, a recent meta-analysis of orthognathic surgery demonstrated predictable occlusion results, rapid tooth positioning for both Class II and Class III malocclusions and dentofacial asymmetry. ${ }^{12}$ These results can be extrapolated to the pediatric population in our series, with good long-term dental outcomes in the context of close follow-up.

Several risks of the BSSMO and transoral odontoidectomy are apparent. Risks of BSSMO include injury to the inferior alveolar nerve, lingual nerve, or mental branch of the inferior alveolar artery as a result of excessive traction or direct injury while performing the osteotomies. In this small case series, no patient experienced neurovascular injury during BSSMO. One of our patients suffered a mucosal infection and pharyngeal wound dehiscence related to the transoral approach. Three patients had hardware-related complications, with 1 patient needing hardware washout because of infection. Two patients also had pressure ulcers because of the cervical immobilization necessary to stabilize the spine after a fusion procedure. A recent meta-analysis by Shriver et al. ${ }^{30}$ of transoral and transnasal odontoid decompression surgeries showed a meningitis risk of $1.0 \%$ and $4.0 \%$, wound infection rate of $3.3 \%$ and $1.9 \%$, and sepsis rate of $2.5 \%$ and $5.1 \%$ for transoral and transnasal procedures, respectively. Our patients experienced postoperative infections, but these were typically associated with posterior decompression and fusion and were not associated with the BSSMO per se. The limited number of patients in this series hinders a definitive conclusion regarding complication rate.

\section{Conclusions}

BSSMO is a safe, versatile method to expand surgical access to the anterior craniocervical junction and subaxial cervical spine in children. This technique may be a helpful adjunct to other traditional surgical approaches and has an acceptable complication rate with the potential to stabilize further neurological deterioration in pediatric patients with severe craniovertebral junction abnormalities and enhance access to the subaxial cervical spine in the setting of severe kyphosis.

\section{References}

1. Al-Habib A, AlAqeel A: C2/3 instability: unusual cause of cervical myelopathy in a child with Down syndrome. Childs Nerv Syst 29:163-165, 2013

2. Al-Moraissi EA, Ellis E: Stability of bicortical screw versus plate fixation after mandibular setback with the bilateral sagittal split osteotomy: a systematic review and meta-analysis. Int J Oral Maxillofac Surg 45:1-7, 2016

3. Bollo RJ, Riva-Cambrin J, Brockmeyer MM, Brockmeyer DL: Complex Chiari malformations in children: an analysis of preoperative risk factors for occipitocervical fusion. $\mathbf{J}$ Neurosurg Pediatr 10:134-141, 2012

4. Brockmeyer DL, Spader HS: Complex Chiari malformations in children: diagnosis and management. Neurosurg $\mathbf{C l i n} \mathbf{N}$ Am 26:555-560, 2015

5. Browd S, Healy LJ, Dobie G, Johnson JT III, Jones GM, Rodriguez LF, et al: Morphometric and qualitative analysis of congenital occipitocervical instability in children: implications for patients with Down syndrome. J Neurosurg 105 (1 Suppl):50-54, 2006

6. Copley LA, Dormans JP: Cervical spine disorders in infants and children. J Am Acad Orthop Surg 6:204-214, 1998

7. Dede O, Thacker MM, Rogers KJ, Oto M, Belthur MV, Baratela W, et al: Upper cervical fusion in children with Morquio syndrome: intermediate to long-term results. J Bone Joint Surg Am 95:1228-1234, 2013

8. Desai SK, Vadivelu S, Patel AJ, Brayton A, Jea A: Isolated cervical spinal canal stenosis at $\mathrm{C}-1$ in the pediatric population and in Williams syndrome. J Neurosurg Spine 18:558563,2013

9. Goldschlager T, Härtl R, Greenfield JP, Anand VK, Schwartz TH: The endoscopic endonasal approach to the odontoid and its impact on early extubation and feeding. J Neurosurg 122:511-518, 2015 
10. Hall BD, Cadle RG, Golabi M, Morris CA, Cohen MM Jr: Beare-Stevenson cutis gyrata syndrome. Am J Med Genet 44:82-89, 1992

11. Hankinson TC, Grunstein E, Gardner P, Spinks TJ, Anderson RC: Transnasal odontoid resection followed by posterior decompression and occipitocervical fusion in children with Chiari malformation Type I and ventral brainstem compression. J Neurosurg Pediatr 5:549-553, 2010

12. Huang CS, Hsu SS, Chen YR: Systematic review of the surgery-first approach in orthognathic surgery. Biomed J 37:184-190, 2014

13. Kanamori Y, Miyamoto K, Hosoe H, Fujitsuka H, Tatematsu N, Shimizu K: Transoral approach using the mandibular osteotomy for atlantoaxial vertical subluxation in juvenile rheumatoid arthritis associated with mandibular micrognathia. J Spinal Disord Tech 16:221-224, 2003

14. Kim IS, Hong JT, Sung JH, Byun JH: Vertical reduction using atlantoaxial facet spacer in basilar invagination with atlantoaxial instability. J Korean Neurosurg Soc 50:528-531, 2011

15. Kim LJ, Rekate HL, Klopfenstein JD, Sonntag VK: Treatment of basilar invagination associated with Chiari I malformations in the pediatric population: cervical reduction and posterior occipitocervical fusion. J Neurosurg 101 (2 Suppl):189-195, 2004

16. Lee JY, Lega B, Bhowmick D, Newman JG, O’Malley BW Jr, Weinstein GS, et al: Da Vinci Robot-assisted transoral odontoidectomy for basilar invagination. ORL J Otorhinolaryngol Relat Spec 72:91-95, 2010

17. Liu JK, Patel J, Goldstein IM, Eloy JA: Endoscopic endonasal transclival transodontoid approach for ventral decompression of the craniovertebral junction: operative technique and nuances. Neurosurg Focus 38(4):E17, 2015

18. Magrini S, Pasquini E, Mazzatenta D, Mascari C, Galassi E, Frank G: Endoscopic endonasal odontoidectomy in a patient affected by Down syndrome: technical case report. Neurosurgery 63:E373-E374, 2008

19. McDowell MM, Hanft SJ, Greenberg SA, Rahmati R, Carrao $\mathrm{V}$, Eisig S, et al: Resection of an upper cervical aneurysmal bone cyst and spinal reconstruction using a midline mandibular osteotomy in a pediatric patient. J Neurosurg Pediatr 13:622-625, 2014

20. McGirt MJ, Attenello FJ, Sciubba DM, Gokaslan ZL, Wolinsky JP: Endoscopic transcervical odontoidectomy for pediatric basilar invagination and cranial settling. Report of 4 cases. J Neurosurg Pediatr 1:337-342, 2008

21. Menezes AH: Surgical approaches: postoperative care and complications "transoral-transpalatopharyngeal approach to the craniocervical junction". Childs Nerv Syst 24:1187-1193, 2008

22. Monson LA: Bilateral sagittal split osteotomy. Semin Plast Surg 27:145-148, 2013

23. Na HY, Choi EJ, Choi EC, Kim HJ, Cha IH, Nam W: Modified mandibulotomy technique to reduce postoperative complications: 5-year results. Yonsei Med J 54:1248-1252, 2013

24. Ow A, Cheung LK: Skeletal stability and complications of bilateral sagittal split osteotomies and mandibular distraction osteogenesis: an evidence-based review. J Oral Maxillofac Surg 67:2344-2353, 2009

25. Park J, Scheer JK, Lim TJ, Deviren V, Ames CP: Biomechanical analysis of Goel technique for $\mathrm{C} 1-2$ fusion. J Neurosurg Spine 14:639-646, 2011

26. Patel AJ, Boatey J, Muns J, Bollo RJ, Whitehead WE, Giannoni CM, et al: Endoscopic endonasal odontoidectomy in a child with chronic type 3 atlantoaxial rotatory fixation: case report and literature review. Childs Nerv Syst 28:1971-1975, 2012
27. Piccirilli CB, Chadduck WM: Cervical kyphotic myelopathy in a child with Morquio syndrome. Childs Nerv Syst 12:114-116, 1996

28. Schreuder WH, Jansma J, Bierman MW, Vissink A: Distraction osteogenesis versus bilateral sagittal split osteotomy for advancement of the retrognathic mandible: a review of the literature. Int J Oral Maxillofac Surg 36:103-110, 2007

29. Shah A: Morphometric analysis of the cervical facets and the feasibility, safety, and effectiveness of Goel inter-facet spacer distraction technique. J Craniovertebr Junction Spine 5:9-14, 2014

30. Shriver MF, Kshettry VR, Sindwani R, Woodard T, Benzel EC, Recinos PF: Transoral and transnasal odontoidectomy complications: A systematic review and meta-analysis. Clin Neurol Neurosurg 148:121-129, 2016

31. Sinha S, Mirza S, Bishop N, Zaki H, McMullan J: Endoscopic endonasal resection of the odontoid peg for paediatric basilar invagination. Br J Neurosurg 26:487-489, 2012

32. Solanki GA, Lo WB, Hendriksz CJ: MRI morphometric characterisation of the paediatric cervical spine and spinal cord in children with MPS IVA (Morquio-Brailsford syndrome). J Inherit Metab Dis 36:329-337, 2013

33. Tan LA, Straus DC, Traynelis VC: Cervical interfacet spacers and maintenance of cervical lordosis. J Neurosurg Spine 22:466-469, 2015

34. Tomatsu S, Mackenzie WG, Theroux MC, Mason RW, Thacker MM, Shaffer TH, et al: Current and emerging treatments and surgical interventions for Morquio A syndrome: a review. Res Rep Endocr Disord 2012:65-77, 2012

35. Tubbs RS, Demerdash A, Rizk E, Chapman JR, Oskouian RJ: Complications of transoral and transnasal odontoidectomy: a comprehensive review. Childs Nerv Syst 32:55-59, 2016

36. Türe U, Pamir MN: Extreme lateral-transatlas approach for resection of the dens of the axis. J Neurosurg 96 (1 Suppl):73-82, 2002

37. Vishteh AG, Beals SP, Joganic EF, Reiff JL, Dickman CA, Sonntag VK, et al: Bilateral sagittal split mandibular osteotomies as an adjunct to the transoral approach to the anterior craniovertebral junction. Technical note. J Neurosurg 90 (2 Suppl):267-270, 1999

38. Youssef CA, Smotherman CR, Kraemer DF, Aldana PR: Predicting the limits of the endoscopic endonasal approach in children: a radiological anatomical study. J Neurosurg Pediatr 17:510-515, 2016

\section{Disclosures}

The authors report no conflict of interest concerning the materials or methods used in this study or the findings specified in this paper.

\section{Author Contributions}

Conception and design: Bollo, Brockmeyer. Acquisition of data: Bollo, Karsy. Drafting the article: Bollo, Karsy, Moores. Critically revising the article: all authors. Reviewed submitted version of manuscript: all authors. Approved the final version of the manuscript on behalf of all authors: Bollo.

\section{Correspondence}

Robert J. Bollo, Division of Pediatric Neurosurgery, Primary Children's Hospital, 100 N Mario Capecchi Dr., Ste. 3850, Salt Lake City, UT 84113. email: robert.bollo@hsc.utah.edu. 